Adıyaman Üniversitesi Sağlık Bilimleri Dergisi, 2020;6(1):29-40

doi:10.30569.adiyamansaglik.624148

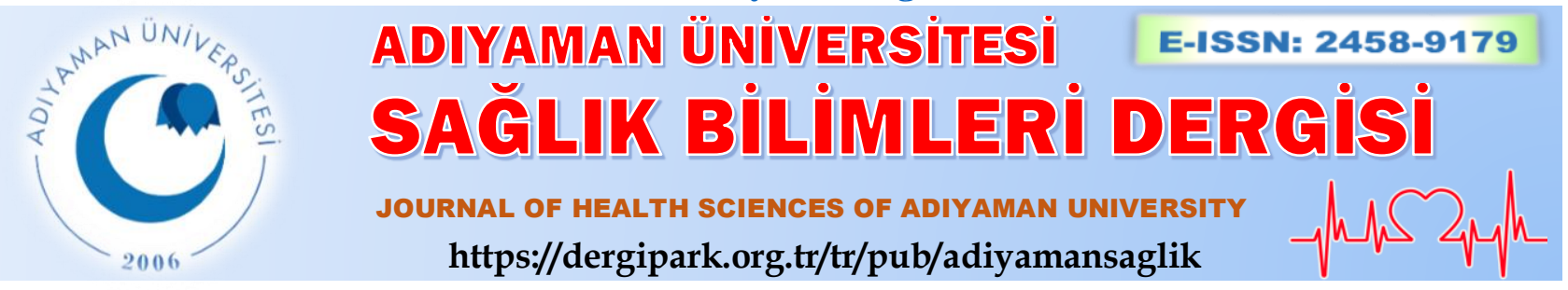

Özgün Araştırma/Research Article

\title{
Subkutan venöz port katater uygulamalarımızın değerlendirilmesi: 6 yıllık klinik tecrübemiz
}

\section{The evaluation of subcutaneous venous port catheter applications: 6 years of our clinical experience}

\author{
Cengiz GÜVEN1@(D) \\ ${ }^{1}$ Adıyaman Üniversitesi, Tıp Fakültesi. Kalp ve Damar Cerrahisi Anabilim Dalı, 02040, Adıyaman-Türkiye
}

Atıf gösterme/Cite this article as: Güven C. Subkutan venöz port katater uygulamalarımızın değerlendirilmesi: 6 yıllık klinik tecrübemiz. ADYÜ Sağlık Bilimleri Derg. 2020;6(1):29-40. doi:10.30569.adiyamansaglik.624148

\section{$\ddot{O} \mathbf{z}$}

Amaç: $\mathrm{Bu}$ çalışmada amacımız, malignite tanısı ile port kateter implante edilen hastaları retrospektif olarak incelemek ve deneyimlerimizi paylaşmaktır.

Gereç ve Yöntem: Ağustos 2012-Aralık 2018 tarihleri arasında Adıyaman Üniversitesi Tıp Fakültesi Kalp ve Damar Cerrahisi Kliniğinde malignensi tanısıyla port kateteri takılan hastalar çalışmaya dâhil edildi. Toplam 231 hasta (97 kadın, 134 erkek) retrospektif olarak, hastane veri kayit sisteminden incelenerek verileri (demografik veri, venöz erişim yolu, teknik ve komplikasyonlar) topland1.

Bulgular: Yapılan dosya taramasında hastaların en geç 2 gün sonra kateterden kemoterapi aldıkları tespit edildi. Postoperatif takiplerde; 7 hastamızda kateter trombozu, 1 hastamızda kateter enfeksiyonu, 4 hastamızda kateter tünel bölgesinde hematom, 40 hastamızda ciltte ekimoz oluştuğu ve obez 1 hastamızda rezervuarın ters döndüğü tespit edildi. Subkutan yağ dokusu zayıf olan bir hastamızda ise rezervuarın cildi erode ederek cilt nekrozu oluşturduğu görüldü.

Sonuç: Subkutan venöz port kateteri kanser hastalarında etkin ve güvenilir bir venöz erişim yoludur. Uygun teknik ve tecrübeli ellerle yapıldığı taktirde minimal komplikasyon ve uzun süreli bir venöz erişim yolu sağlar.

Anahtar Kelimeler: Kanser; Kemoterapi; Venöz port kateter; Komplikasyon.

\begin{abstract}
Aim: Our aim in this study is to retrospectively examine patients who were implanted a port catheter with a diagnosis of malignancy and share our experiences.

Materials and Methods: The patients who had admission to port catheter with the diagnosis of malignancy between August 2012 and December 2018 at Adiyaman University Faculty of Medicine Cardiovascular Surgery Clinic were included in the study. A total of 231 patients (97 females, 134 males) were analyzed retrospectively from the hospital data recording system (demographic data, venous access, technique and complications).

Results: In the file scan, it was found that the patients had received chemotherapy from the catheter in no later than 2 days. In terms of complication, it was determined that catheter thrombosis was found in 7 patients, catheter infection in 1 patient, hematoma in the catheter tunnel area in 4 patients, skin ecchymosis in 40 patients and the reversal of the reservoir in 1 obese patient was detected. In one patient with weak subcutaneous adipose tissue, it was determined that the reservoir had caused skin necrosis by eroding the skin. Conclusion: Subcutaneous venous port catheter is an effective and reliable venous access in cancer patients. It provides minimal complications and long-term venous access on condition that it is performed with appropriate techniques and experienced hands.
\end{abstract}

Keywords: Cancer; Chemotherapy; Venous port catheter; Complication.

Yazışma Adresi/Address for Correspondence: Dr. Cengiz GÜVEN, Adıyaman Üniversitesi, Tıp Fakültesi, Kalp ve Damar Cerrahisi Anabilim Dal1, 02040, Adıyaman-Türkiye E-mail: guvencengz@ yahoo.com

Geliş Tarihi/Received:26.09.2019 Kabul Tarihi/Accepted:17.03.2020 Yayım Tarihi/Published online:23.04.2020 


\section{Giriş}

Kanser hastaları uzun süren tedavi protokollerinde en fazla sıkıntı çektikleri durumlardan biri de uygun bir venöz erişim yoludur. Kemoterapide kullanılan bazı ilaçların uygulanması sırasında vasküler toksik etkileri nedeniyle, s1k sık alınan kan örnekleri, uygulanan antibiyotik tedavileri, parenteral nutrisyon tedavileri için ve acil durumlarda kullanılabilecek kalıcı ve uzun süreli kullanılabilen bir vasküler erişim yoluna ihtiyaç kaçınılmazdır. $\mathrm{Bu}$ amaçla kullanılan subkutan venöz port kateter (SKVPK)'leri vücut dişında görünür olmamas1, hasta tarafindan iyi tolere edilmesi ve enfeksiyon riskinin düşük olması nedeniyle s1k tercih edilir ve güvenli bir intravenöz erişim sağlarlar. ${ }^{1,2}$

SKVPK işlemlerinde pnömo-hemotoraks, karotiko-juguler arteriyovenöz fistül, kateter enfeksiyonu, tromboz, malpozisyon, kateterin king yapmas1 veya kırılmas1, emboli, siv1 ekstravazasyonu, frenik veya brachial flexus hasar1, aritmi ve kardiyak rüptür gibi komplikasyonlar tarif edilmiştir. ${ }^{3}$ Ancak uygun ve deneyimli bir ekip tarafindan takıldığ 1 taktirde kullanım süresi ile kıyaslandığında minimal komplikasyonlar ile iyi tolere edilirler. Her ne kadar literatür taramasında bu işi onkolog, radyolog ve cerrahların üstlendiği gösterilse de komplikasyonları zamanında ve hızlı karşılamak noktasında cerrahların (özellikle kardiyovasküler cerrahların) bu işi üstlenmesi gerekliliği ortaya çıkmaktadır., ${ }^{4,5} \mathrm{Bu}$ çalışmadaki amacımız deneyimli tek bir kardiyovasküler cerrahi ekip tarafindan kanser tanisı alan hastalara takılan SKVPK'leri retrospektif olarak incelenmek ve literatür eşliğinde altı yıllık sonuçlarımızı paylaşmaktır.

\section{Gereç ve Yöntem}

\section{Araştırmanın Tipi}

Dosya kullanılarak yapılan retrospektif arşiv taramasıdır.

\section{Araştırmanın Evreni ve Örneklemi}

$\mathrm{Bu}$ çalışmada 2012 Ağustos-2018 Aralık tarihleri arasında onkoloji kliniğince, kalp ve damar cerrahisi kliniğimize refere edilen ve SKVPK takılan toplam 231 hasta retrospektif olarak incelendi.

\section{Verilerin Analizi}

Veriler IBM SPSS 22.0 paket programı kullanılarak, yaş, cinsiyet, komplikasyon oranı, işlem sonrası kullanım süresi, cerrahi yöntem açısından incelendi. Normal dağılım gösteren verilerin sonuçları ortalama \pm SD olarak normal dağılım göstermeyen veriler ise medyan (min-maks) olarak verildi. Kategorik verilerin analizinde Ki-Kare homojenlik testi kullanıldı. Sonuçlar frekans ve yüzde olarak verildi. Anlamlilik seviyesi en az $p<0.05$ olarak kabul edildi.

\section{Araştırmanın Etik Boyutu}

Çalışma retrospektif elektronik dosya taraması şeklinde yapıldığı için araştırmaya dahil edilen hastalardan onam alınmadi. İlgili üniversitenin Girişimsel Olmayan Klinik Araştırmalar Etik Kurulu'ndan gerekli izin alındiktan sonra (17.09.2019-2019/6-1) başlandı. Yazar, çalışmaya dahil edilen gönüllüler üzerinde yapılan tıbbi araştırmalarda, etik ilkeler hususunu içeren Helsinki Bildirgesi'ne ve geliştirilmiş en son şekline uyarak çalışmayı gerçekleştirmiştir.

Girişimsel teknik: Kateter steril ameliyathane ortaminda elektrokardiyografi (EKG, puls oksimetre ve non invaziv kan basınc1 monitorizasyonu ile takıldığı tespit edildi. Uygun boyama (povidon iyot) ve örtünmeyi takiben ponksiyon bölgesi, port cebi ve tünel bölgesi minimal ağrı için 22 gauge (22G) enjektör iğnesi ile \%2'lik lidokain veya prilokain kullanılarak anestetize edildiği dosya taramasından anlaşıldı.

İnternal juguler ven (İJV) tercihlerinde hasta hafif trendelenburg pozisyonunda karş1 tarafa bakacak şekilde pozisyon verildi (Şekil 1). Sternokleidomastoid kasin lateral ve mediyal bacaklarının oluşturduğu üçgenin tepesinden ponksiyon yapildı. Ponksiyon surasında diğer el ile arter palpe edildi ve nabzın alındığ 1 parmağın lateralinden girildi. ${ }^{6}$ Ponksiyonda 22G uçlu enjektör kullanıldı. 


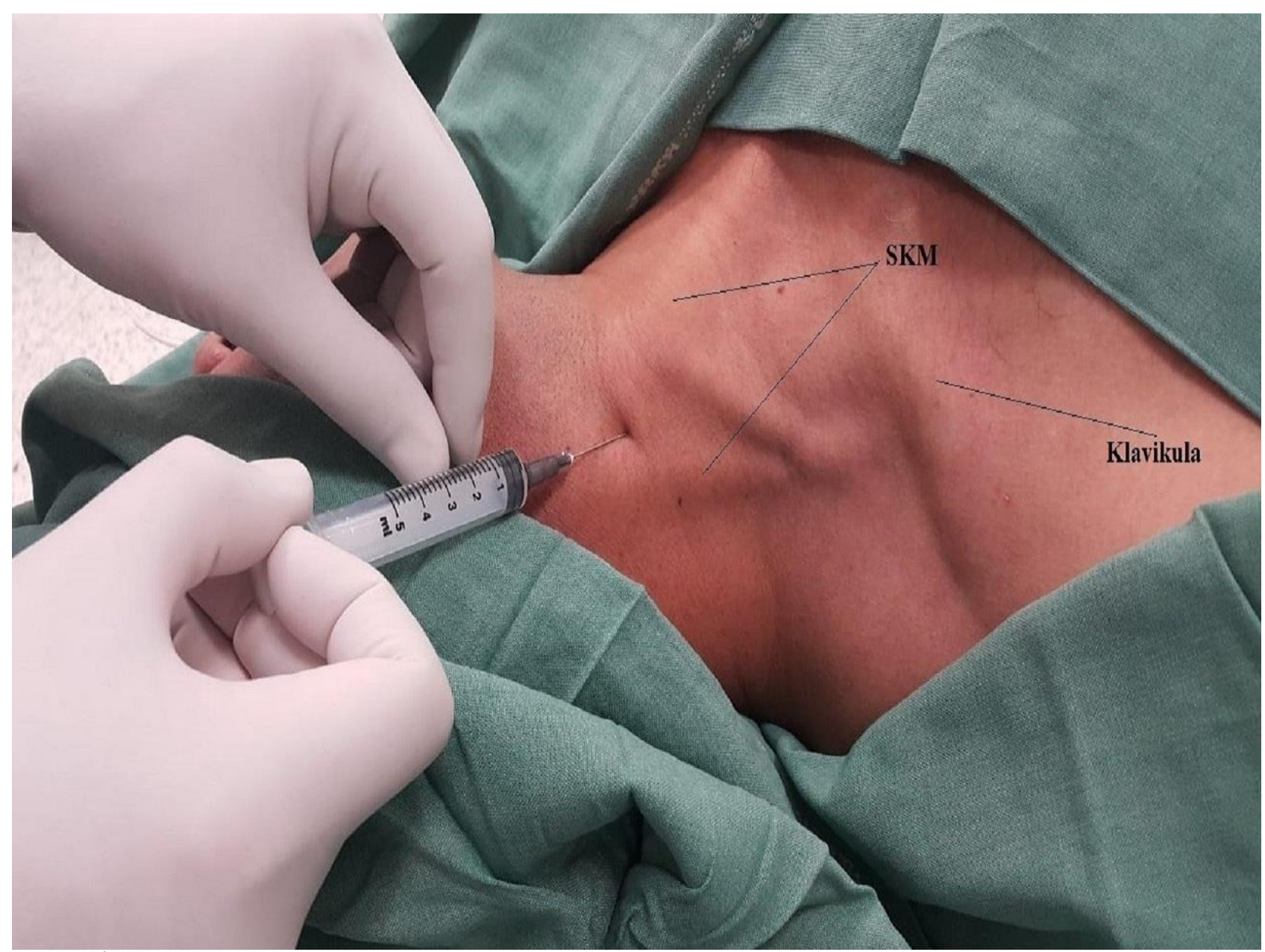

Şekil 1. İnternal juguler ven ponksiyonu. (SKM; sternokleidomastoid kas (Şekildeki ok))

Böylece muhtemel arter ponksiyonlarında hematom oluşması önlenmiş oldu. Ven trasesi $22 \mathrm{G}$ enjektör ile tespit edildikten sonra 10 french (10Fr) kateter giriş iğnesi ile İJV ponksiyone edildi.

Subklavyan ven (SCV) tercihlerinde yine hasta hafif trendelenburg pozisyonunda karş1 tarafa bakacak şekilde pozisyon verildi (Şekil 2). Lokal anesteziden sonra $22 \mathrm{G}$ iğne kısa kalabileceğinden direkt kateter iğnesi ponksiyon amaciyla kullanıldı. Teknik olarak klavikulanın orta-lateral 1/3'lük noktasından klavikulanın altı sıyrılarak iğne ucu sternal çentik ve karşı omuza doğru horizontal ilerletilerek ven ponksiyone edildi. ${ }^{6}$ Eş zamanlı yardımcı bir sağlık personeli aynı taraf kolu vücuda paralel bir şekilde aşağıya doğru çekti. Bu aşamalardan sonraki teknik İJV ve SCV için ortak idi. Klavuz tel kateter iğnesinden ven lümenine gönderildi. Kılavuz tel giriş bölgesindeki cilt yaklaşık 3-4mm'lik bir kesi ile genişletildi. Hasta üzerinde uygun kateter boyu hesaplandi. Port cebi meme üzerinden yaklaşı 2-3 cm proksimalde olacak şeklinde ayarlandı. 2-3 cm'lik kesi yapılarak künt disseksiyonlar ile rezervuarın yerleşebileceği büyüklükte subkütan cep oluşturuldu. Tünel oluşturucu ile kateter cep bölgesinde subkutan dokudan geçirilerek genişletilen ven ponksiyon bölgesinden çıkartıldı. Dilatatör ve kılıf, kılavuz tel üzerinden dairesel hareketlerle ven lümenine ilerletildi. Hastaya valsavla manevras1 yapılarak kilit mekanizması açıldı ve klavuz tel ve dilatatör kılıf içinden çıkartıldı. Port kateteri kılıf içerisinden daha önce ölçülen boyda gönderildi. Kılıf iki yandan açılarak çıkartıldı. Port heparinize mayi ile havası alınarak yıkandı. Rezervuar subkutan cebe yerleştirilerek iki noktadan 3/0 vikril ile tespit edildi. Kateter ve rezervuar konnekte edilerek kilitlendi. Rezervuar kesisi 3/0 prolen ile kapatıldı. Son olarak rezervuardaki hava da alınarak tüm sistem yeniden heparinize mayi ile yıkand1. 


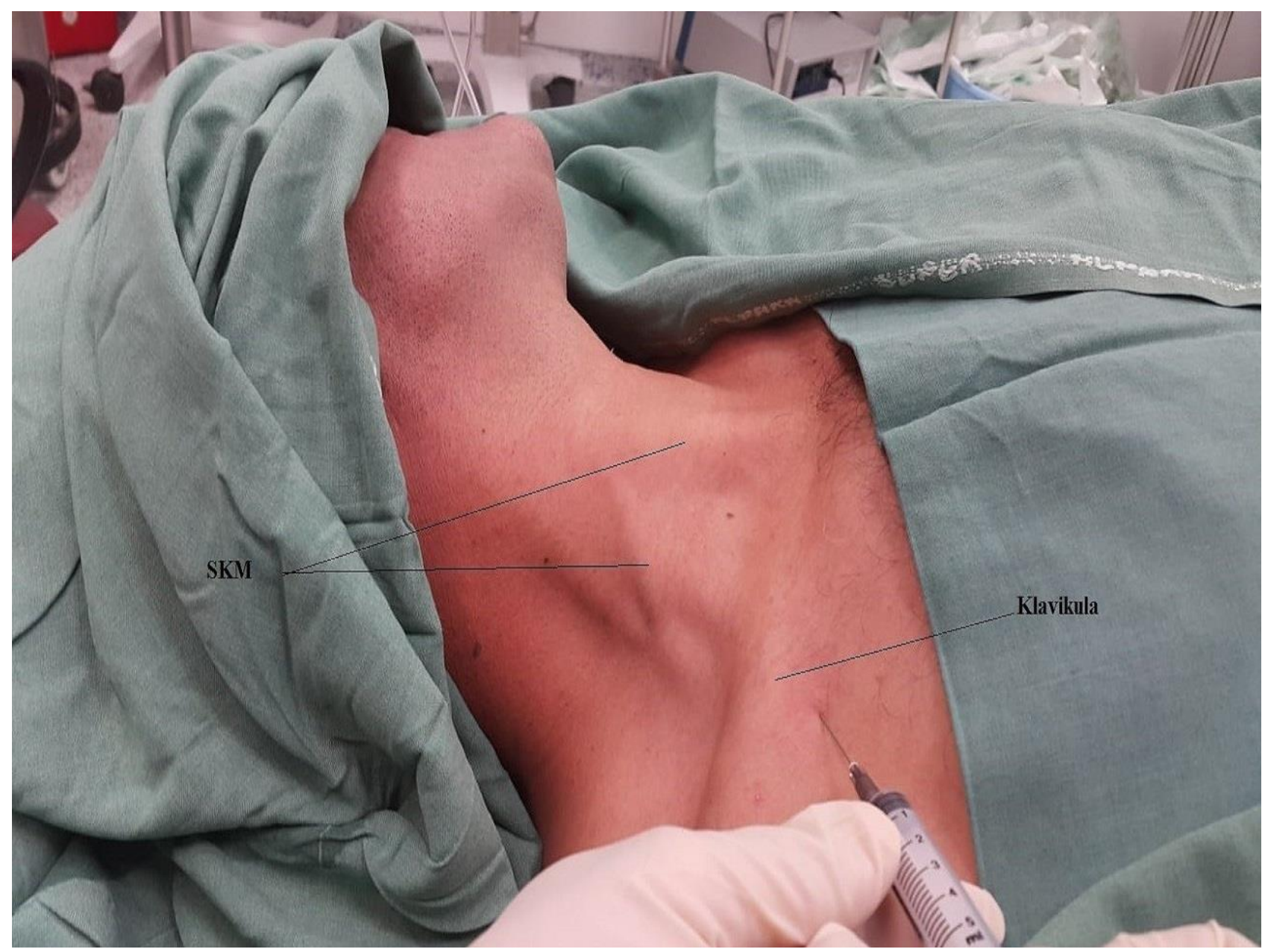

Şekil 2. Subclavien ven ponksiyonu (SKM; sternokleidomastoid kas).

Kateter boyunun hesaplanmasi; Ponksiyon bölgesi ve rezervuar arasındaki uzunluk işaretlendi (Şekil 3. [AC], subkutan uzunluk). Klavuz tel, EKG rehberliğinde aritmi oluşuncaya kadar ven lümenine ilerletildi. Aritmi oluştuktan sonra klavuz tel kalp ritmi normale dönünceye kadar yaklaşık 2-3 cm geri çekildi. Tel üzerindeki markırlarla ölçüm alındı (Şekil 3. [AB], intravasküler uzunluk). $\mathrm{Bu}$ iki değerin toplamı ([AB]+[AC]) yaklaşık kateter boyunu veriyordu. $\mathrm{Bu}$ yöntem kullanılarak port kateter takılan hiçbir hastamızda kalıcı bir aritmi tespit edilmedi. İşlem sonrası çekilen PA akciğer grafisinde tüm hastalarımızda kateter ucunun ya atriyokaval bileşkede ya da sağ atriyumda olduğu görüldü.

\section{Bulgular}

Kalp ve damar cerrahisi kliniğimizde Ağustos 2012-Aralık 2018 tarihleri arasında malignite tanısıyla toplam 231 hastaya (97 kadın, 134 erkek) SKVPK takıldı. Hastalara ait demografik veriler Tablo 1 'de özetlenmiştir.

Yaş ortalaması $58.88 \pm 15.22$, ortanca yaş 59 yıl idi. Dünya Sağlık Örgütüne göre yaş gruplar1 ergen (0-17), genç yaş aralığ1 (18$65)$, orta yaş aralığ 1 (66-79) ve yaşlı (80 yıl ve üstü) olarak sinıflandırılır ise ergen yaş grubunda 1(\%0,43), genç yaş grubunda $144(\% 62,33)$, orta yaş grubunda $65(\% 28,14)$ ve yaşlı grubunda $21(\% 9,1)$ hastaya kateter yerleştirildiği tespit edildi (Tablo 1). Ergen yaş gurubu hariç tüm yaş gruplarında en sık endikasyon kolon kanseri (CA) nedeniyle kemoterapi alacak hastalardan oluşuyordu (Şekil 4).

Dosya taramasından venöz erişim yolu olarak en sik $181(\% 78)$ hasta ile sağ İJV kullanıldığ 1 tespit edildi. Daha sonra sirayla 25 (\%11) hastada sol İJV, 13 (\%6) hastada sağ SCV ve $12(\% 5)$ hastada ise sol SCV kullanıldığı görüldü (Şekil 5). 


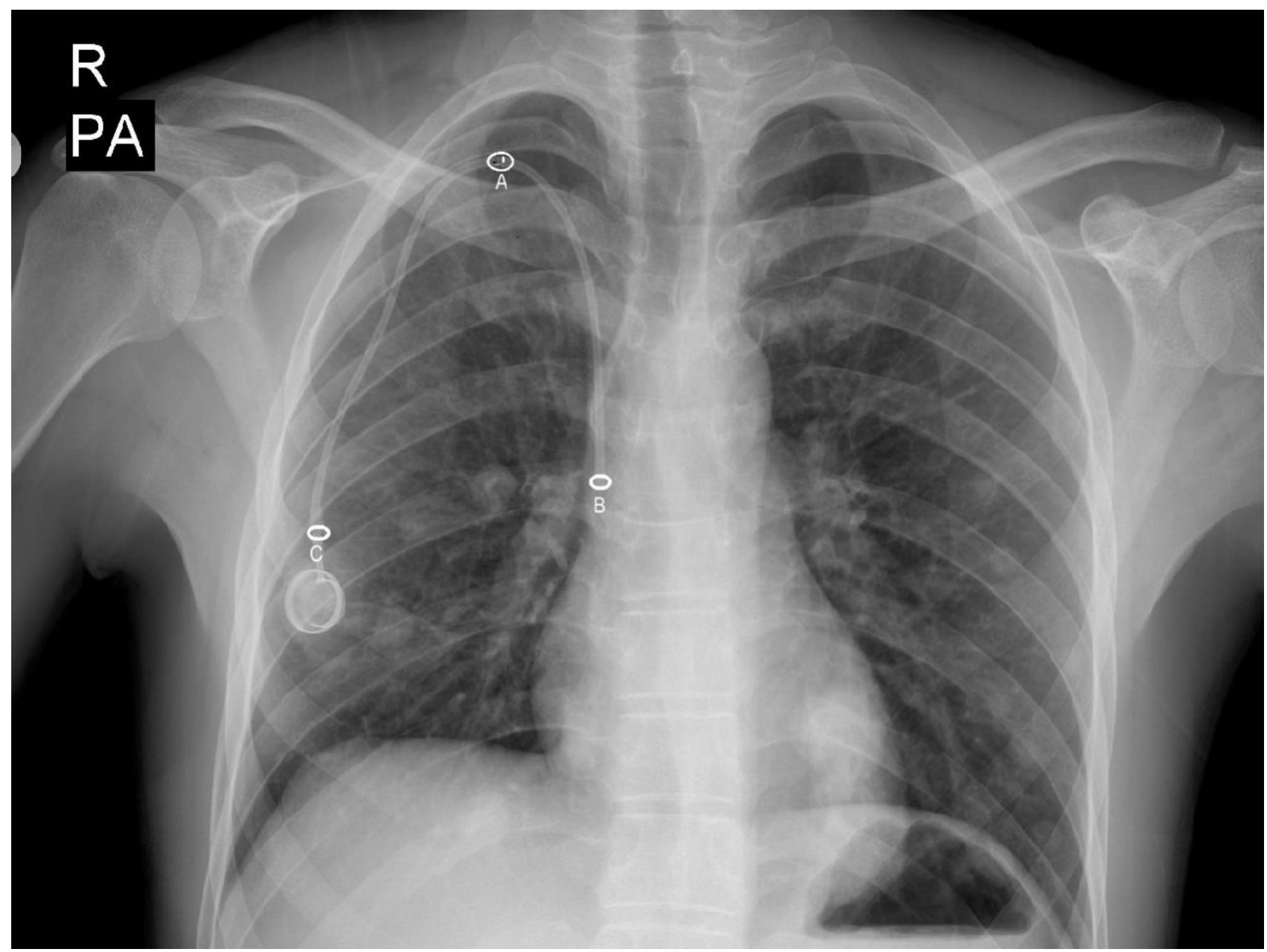

Şekil 3. Kateter boyu=[AB] (intravasküler parça) $+[A C]$ (subkutan parça).

$\mathrm{A}=$ ponksiyon bölgesi (kateterin ven lümenine giriş bölgesi), $\mathrm{B}=\mathrm{kateter}$ ucunun bulunduğu bölge(atriyokaval bileşke veya sağ atriyum), $\mathrm{C}=\mathrm{kateter}$ ile rezervuar bileşkesi (buradaki marker kateterin total boyunu gösterir)

Ortalama port günü $348,26 \pm 256,67$ (Aralı; 65-718) ve toplam port günü 69,067 gün idi. Hiçbir hastamızda profilaktik antibiyotik yapılmadığ1 ve tüm işlemlerin lokal anestezi (\%2 lidokain veya prilokain) altında gerçekleştirildiği görüldü.

Komplikasyon olarak 7 hastada kateter trombozu, 4 hastada kateter tünel yerinde hematom geliştiği, 40 hastamızda tünel bölgesinde cilt-altı ekimoz gibi minör komplikasyonların oluştuğu dosya taramasından anlaşıldı (Tablo 2). Obez bir hastada muhtemelen tespit süturlarının açılarak rezervuarın ters döndüğü ve bu hastanın lokal anestezi ile rezervuar cebi açılarak revize edildiği tespit edildi. Cilt altı yağ dokusu zayıf bir hastamızda ise 9 ay sonraki kontrolerinde rezervuarın cildi erode ederek cilt nekrozu oluşturduğu ve bir kısmının cilt dışına çıktığı, yine lokal anestezi altında cilt debritmanı yapilarak yeniden cep oluşturulduğu ve rezervuarın yeni cebe yerleştirildiği anlaşıldı. Bunun dişında çalışma serimizdeki 231 hastamızın hiçbirinde ek bir komplikasyon görülmedi.

Tüm hastalarda muhtemel komplikasyon ihtimaline karşı işlemden hemen sonra Postero-anterior (PA) akciğer grafisi ile kontrol edildiği, kateterlerde king veya malpozisyon gözlenmediği ve tüm kateterlerin kavoatriyal bileşkenin hemen üstünde veya sağ atriyumda olduğu görüldü. Komplikasyon olarak kateter trombozu görülen 7 hastamızın 4'ünde rekombinant insan doku plazminojen aktivatörü (rt-PA) ile başarılı bir şekilde tedavi edildiği, diğer 3 hastamızda ise bu tedavinin başarısız olduğu ve kateter değişimine gidildiği tespit edildi. 
Tablo 1. Hastaların demografik özellikleri

\begin{tabular}{|c|c|}
\hline \multicolumn{2}{|l|}{ Cinsiyet } \\
\hline Kadın & $97(\% 42)$ \\
\hline Erkek & $134(\% 58)$ \\
\hline Yaş Ort. & $58,88 \pm 15,22$ \\
\hline \multicolumn{2}{|l|}{ Port günü } \\
\hline Ortalama & $348,26 \pm 256,67$ \\
\hline Aralık & $65-718$ \\
\hline Toplam & 69.069 \\
\hline \multicolumn{2}{|c|}{ Kateter uzunluğu(cm) } \\
\hline Sağ İJV & $17,54 \pm 3,7$ \\
\hline Sol İJV & $19,45 \pm 2,19$ \\
\hline Sağ SCV & $16,67 \pm 2,93$ \\
\hline Sol SCV & $20,56 \pm 2,36$ \\
\hline \multicolumn{2}{|l|}{ Malignensi } \\
\hline Kolon & $106(\% 45.9)$ \\
\hline Mide & $35(\%$ 15.2) \\
\hline Meme & $24(\% 10,4)$ \\
\hline Akciğer & $15(\% 6,5)$ \\
\hline Mezotelyoma & $7(\% 3,03)$ \\
\hline Pankreas & $7(\% 3,03)$ \\
\hline Rektum & $7(\% 3,03)$ \\
\hline Safra kesesi & $5(\% 2,2)$ \\
\hline Endometriyum & $4(\% 1,7)$ \\
\hline Liposarkom & $3(\% 1,3)$ \\
\hline Prostat & $3(\% 1,3)$ \\
\hline Karaciğer & $3(\% 1,3)$ \\
\hline Larinks & $2(\% 0,8)$ \\
\hline Nazofarinks & $2(\% 0,8)$ \\
\hline Duodenum & $2(\% 0,8)$ \\
\hline Diğer & $6(\% 2,6)$ \\
\hline
\end{tabular}

\section{Tartışma}

Kanser tedavisi aylar hatta yıllar sürebilen bir süreçtir. Kanser tipine ve evresine göre değişmekle birlikte cerrahi, radyoterapi, kemoterapi, daha az siklikta hormon ve biyolojik tedavi yöntemleri gibi yöntemler tek başına veya birlikte kullanılabilmektedir. Uzun süren bu tedavilerde kan almak, kan vermek ve sitotoksik ilaçların kullanılması için açılan multipl periferik damar yolları hastayı en çok yıpratan ve psikolojik açıdan etkileyen durumlardandır. ${ }^{7}$ Alt veya üst extremite de sınırlı sayıda damar olduğu için kemoterapi hastalarında uzun vadeli damar erişim yolu bulmak çoğu zaman sorun teşkil edebilir. Kullanılan damarlar da az veya çok kemoterapötik ilaçların sitotoksik ve katastrofik etkileri ile zarar görür. Çoğu zaman kullanılan bir damar bir sonraki seansta kullanılamaz hale gelir. ${ }^{8}$ 1980'li y1llarında santral venöz kateterlerin (SVK) geliştirilmesi ile kanser hastalarında yaşam kalitesi artmıştır. ${ }^{9,10}$ Günümüzde yaygın bir kullanım alanı olan SVK'ler periferik venöz erişim yollarıyla kıyaslandığında daha az enfeksiyon riski, kolay erişilebilir olması, kan alma, kan verme, total parenteral beslenme ve ilaç tedavilerine izin vermesi gibi avantajlara sahiptir. $\mathrm{Bu}$ amaçla kullanılan santral kateterler üç gruba ayrılır; tünelsiz geçici, tünelli kalıcı ve tamamiyla implante edilebilir venöz port kateterler. ${ }^{10}$

İmplante edilebilir port kateterleri dişarda herhangi bir parçasının olmaması ile kemoterapi gibi uzun süren venöz erişim ihtiyaçlarında hem enfeksiyon riskinin az olmas1, hasta tarafindan iyi tolere edilmesi hem de uzun kullanım süresi ile daha çok tercih edilir. ${ }^{11,12}$

Port kateterleri venöz rezervuar ve kateterden oluşan kapalı bir sistemdir (Şekil 6). SKVPK'lerin distal ucu (silikon kateter) atriyokaval bileşke ya da sağ atriyumda yer alır. Erişim bölgesi (rezervuar) göğüs ön duvarı, koltuk altı veya omuz bölgesinde cilt altında oluşturulan bir cebe yerleştirilir. Rezervuar cilt altından kabarı ve elle hissedilebilen kısımdır ve titanyum alaşımdan oluşur. Üst kısmında silikon septum bulunur. Septum port iğnesi ile uygun girildiği takdirde yaklaşık 2000 girişe izin verir. ${ }^{13}$

SKVPK'leri en s1k yaş ve cinsiyete göre değişmekle birlikte; gastrointestinal sistem (kolon ve mide) kadinlarda meme ve erkeklerde akciğer kanseri nedeniyle kullanılır. Serimizdeki hastaların yaş ortalamas1 $58,88 \pm 15,22$ idi ve en s1k gastrointestinal malignite nedeniyle port takılan hastalardan oluşuyordu. Kolon kanseri nedeniyle 104 (\%45), mide kanseri nedeniyle 35 (\%15) ve pankreas kanseri nedeniyle 7 (\%3) hasta ile (Tablo 1) literatürle uyumlu olarak en sık port takılan kanser türleri arasında yer aldığ 1 tespit edildi. ${ }^{8,9}$

SKVPK'leri takılırken daha çok İJV veya SCV tercih edilse de sefalik ven de kullanılabilen venlerdendir. Periferik venler kullanıldığında pnömotoraks veya hemotoraks gibi majör komplikasyonlar görülmez. 


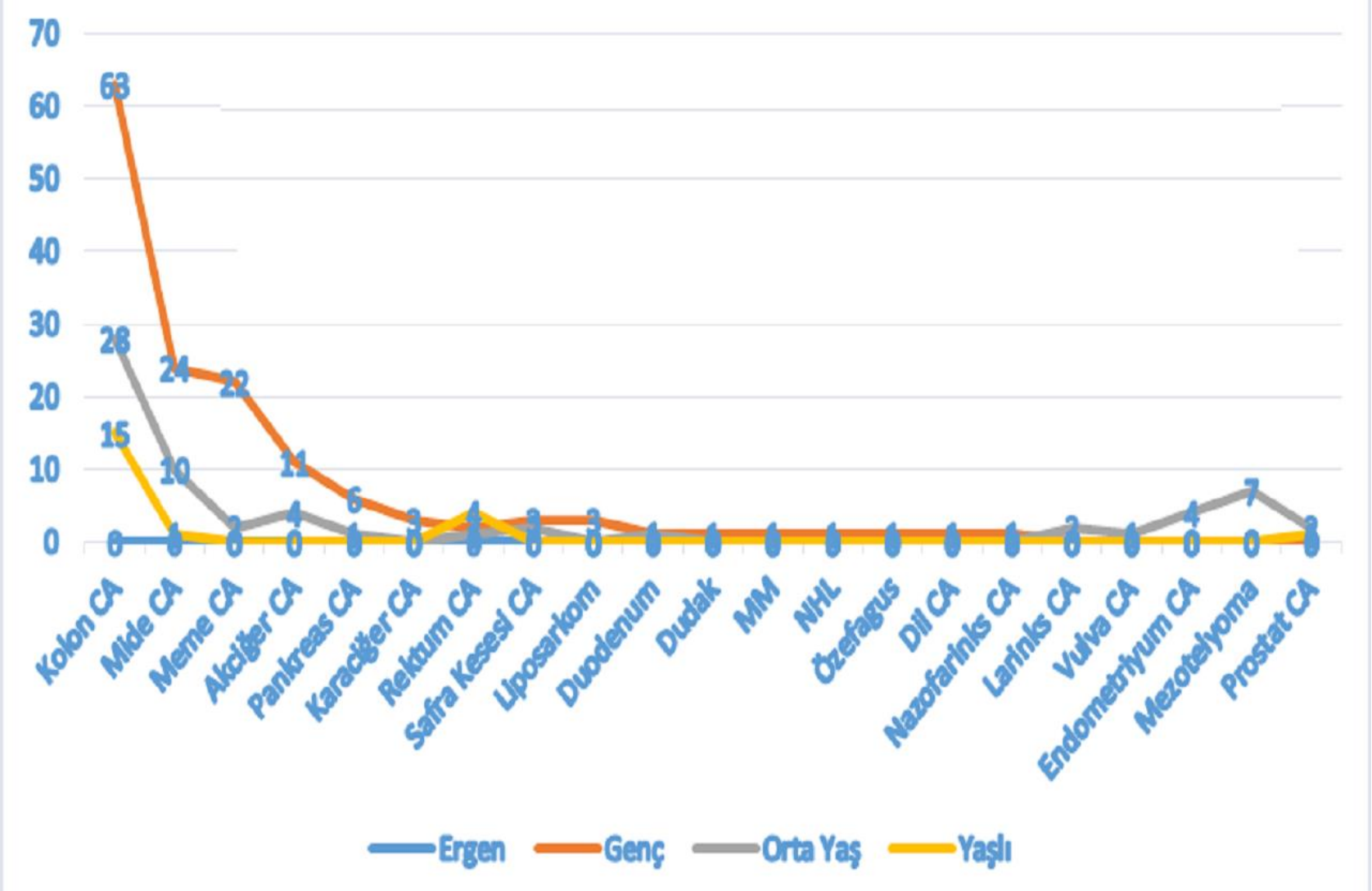

Şekil 4. Yaş gruplarına göre malignite dağılımı.

Tablo 2. Erken ve geç komplikasyonlar.

\begin{tabular}{lccc}
\hline Erken komplikasyonlar & İJV $(\mathrm{n}=206)$ & SCV (n=25) & $\boldsymbol{p}$ değeri \\
Tünel hematomu & $3(\% 1,45)$ & $1(\% 4,0)$ & 0,357 \\
Tünel bölgesinde ekimoz & $37(\% 20)$ & $3(\% 12)$ & 0,406 \\
Pnömotorax-hemotorax & 0 & 0 & 1,00 \\
\hline Geç komplikasyonlar & 0 & $1(\% 4)$ & 0,004 \\
Kateter enfeksiyonu & 0 & $1(\% 4)$ & 0,004 \\
Cilt enfeksiyonu & 0 & 0 & 1,00 \\
Kateter malpozisyonu & 0 & $1(\% 4)$ & 0,004 \\
Rezervuar malpozisyonu & $5(\% 2,43)$ & $2(\% 8)$ & 0,125 \\
Kateter trombozu & $2(\% 1)$ & $1(\% 4)$ & 0,206 \\
Kateter değişimi & 0 & \\
\hline
\end{tabular}

İJV: internal juguler ven, SCV: subklavyan ven. Ki kare testi kullanıldı. Anlamlılık düzeyi $p<0,05$ olarak kabul edildi.

Ancak bu teknikte uzun kateter ihtiyacı ve büyük eklemler geçilirken kateterin zamanla king yapmas1 gibi istenmeyen durumlar meydana gelebilir. İJV ve özellikle SCV gibi santral venler aracıllğ 1 ile takılan portlarda ise akciğer veva kardiyak komplikasyonlar görülebilmektedir. ${ }^{14}$

Bizim çalışma grubundaki hastalarımızda komplikasyon azlığı ve pozisyon olarak erişim kolaylığı nedeniyle sağ İJV (181 hasta\%78) tercih edildi. İJV tercihlerimizdeki tüm hastalarımızda lokal anestezi ve ilk ponksiyonumuz $22 \mathrm{G}$ uçlu (ince iğneli) enjektör ile yapıldı. Böylelikle muhtemel arter ponksiyonunda olası ciddi bir hematomun önüne geçildi. İnce iğne ile ven trasesi tespit edildikten sonra hastaya hareketsiz kalması söylendi ve port iğnesi ile ven ponksiyonu 
yapılarak işleme devam edildi. İşlem sonunda tüm hastalarda tünel bölgesinde hematom oluşmaması için baskılı pansuman ile kapatıldı. 231 hasta serimizde 4 hasta dışında kayda değer bir hematom oluşmad. Bu hastalara ek bir müdahalede bulunulmadığ 1 ve sadece takip edildiği dosya taramasından anlaşıldı. 37 İJV hastamızda ve $3 \mathrm{SCV}$ hastamızda tünel bölgesinde ciltte ekimoz görülmüş ve 2 haftalık medikal tedavi ile iyileştiği görülmüştür.

İVJ tercihlerindeki en önemli dezavantaj kateter açısının dar olmasıydı (Şekil 7A.). Bu da kateterde kırılma, king oluşumu ve tromboz riskini artıran bir faktör olarak karşımıza çıkmaktadır. Serimizdeki 7 kateter trombozunun 5'i İJV kateterlerinde görüldü (Tablo 2). SCV kateterlerinde kateter açısı daha rahat ayarlanabilmektedir (Şekil 7B). Ancak oran olarak bizim serimizde SCV kateterlerinde tromboz oranı \%8'e karşıllk $\% 2,43$ ile daha yüksek olarak bulundu (Tablo 2). Bunun nedeni ise bu iki hastamıdan birinde kateter enfeksiyonu gelişmesi, diğerinde ise tünel bölgesinde hematom oluşumu idi. $\mathrm{Bu}$ iki hasta dişında SCV kateterlerinde tromboz gelişen hastamız olmadi.

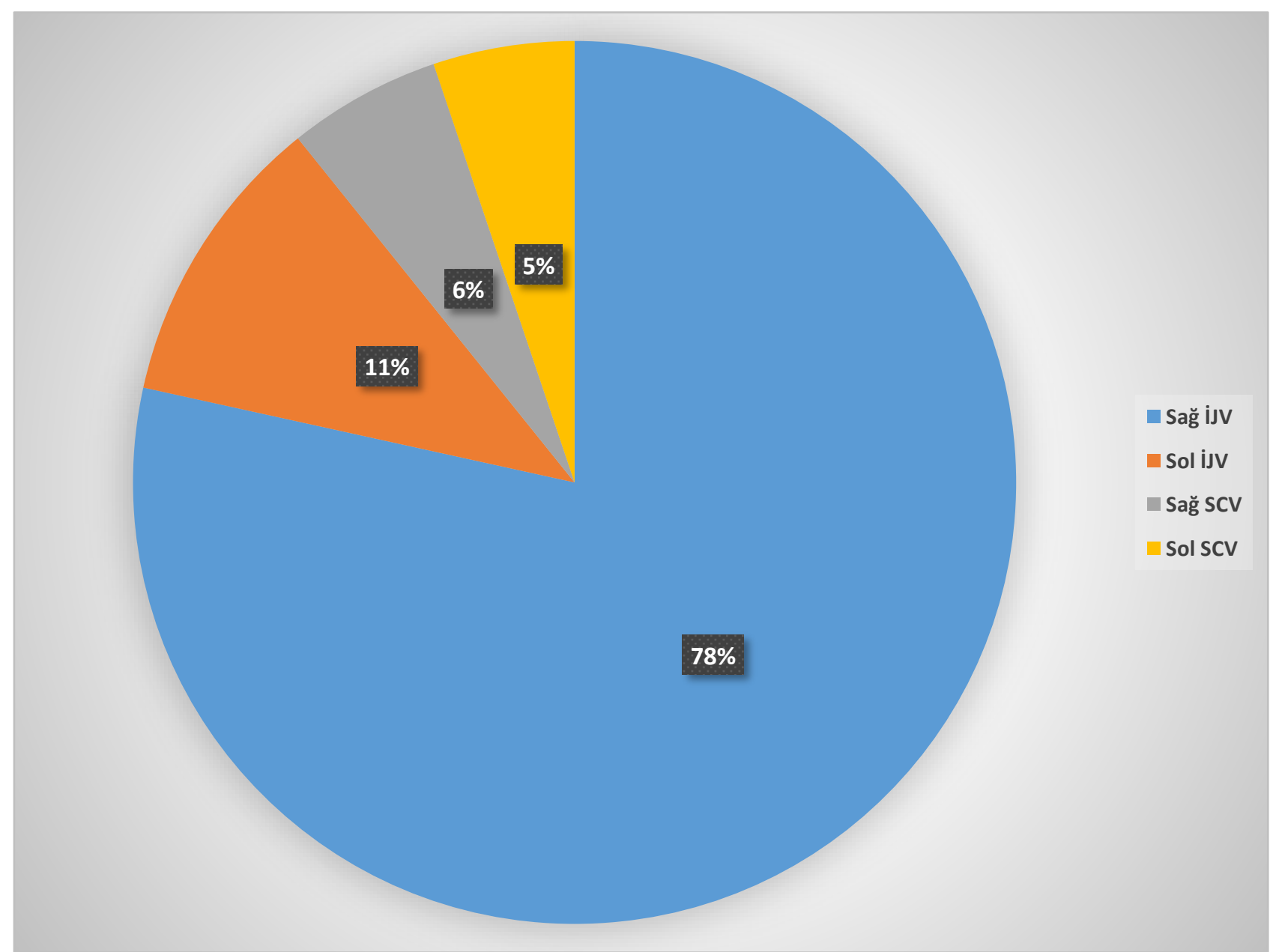

Şekil 5. Venöz erişim yolları (İJV;internal juguler ven, SCV;subklavian ven).

Kateter malfonksiyonu kateterden siv1 vermede ve kan almada zorluk olarak tanımlanabilir. Bu da kateterin king yapması, ilaçların kan ile presipitasyon oluşturarak kateter lümenini tıkaması veya kateter ucunun fibrin ile kaplanması gibi nedenlerle oluşabilir. Ayrıca kateter ucunun ven lümenine dayanması da malfonksiyon nedenlerindendir. Malfonksiyon sıklığ $1 \% 0,8$ 5 ve katater trombozu siklığ $\% 0,7-7$ arasındadır. ${ }^{1,3}$ Bizim hastalarda SCV girişimlerinde $1(\% 4)$, totalde ise yine 1 $(\% 0,4)$ oranında malfonksiyon gözlendi.

Serimizde 231 hastamızın 7'si (\%3) en erken 6 ay sonra kateter trombozu nedeniyle onkoloji kliniğince servisimize konsülte edildiği, bu hastalardan 3'üne rt-PA ile başarılı bir şekilde tedavi edildiği anlaşıldı. Diğer 3 hastada ise trombolitik tedavi 
başarısız olduğu için port kateter değişimine gidilmiştir. Kateter trombozu sıklığı serimizde \%3 oraniyla literatür ile uyumlu idi.

Literatür taramasında SVK takılırken ultrasonografi (USG) kullanmanın komplikasyonları azaltabileceği savunulsa da sürekli aynı cerrahi ekip tarafından yapıldığ 1 takdirde USG kullanmadan körlemesine yapmanın da komplikasyonları azaltılabileceği gösterilmiştir. ${ }^{15}$ Literatürde pnömotoraks ve hemotoraks daha çok subklavien uygulama komplikasyonu olarak $\% 0,1-3,2$ arasında görülmektedir. ${ }^{1,3}$

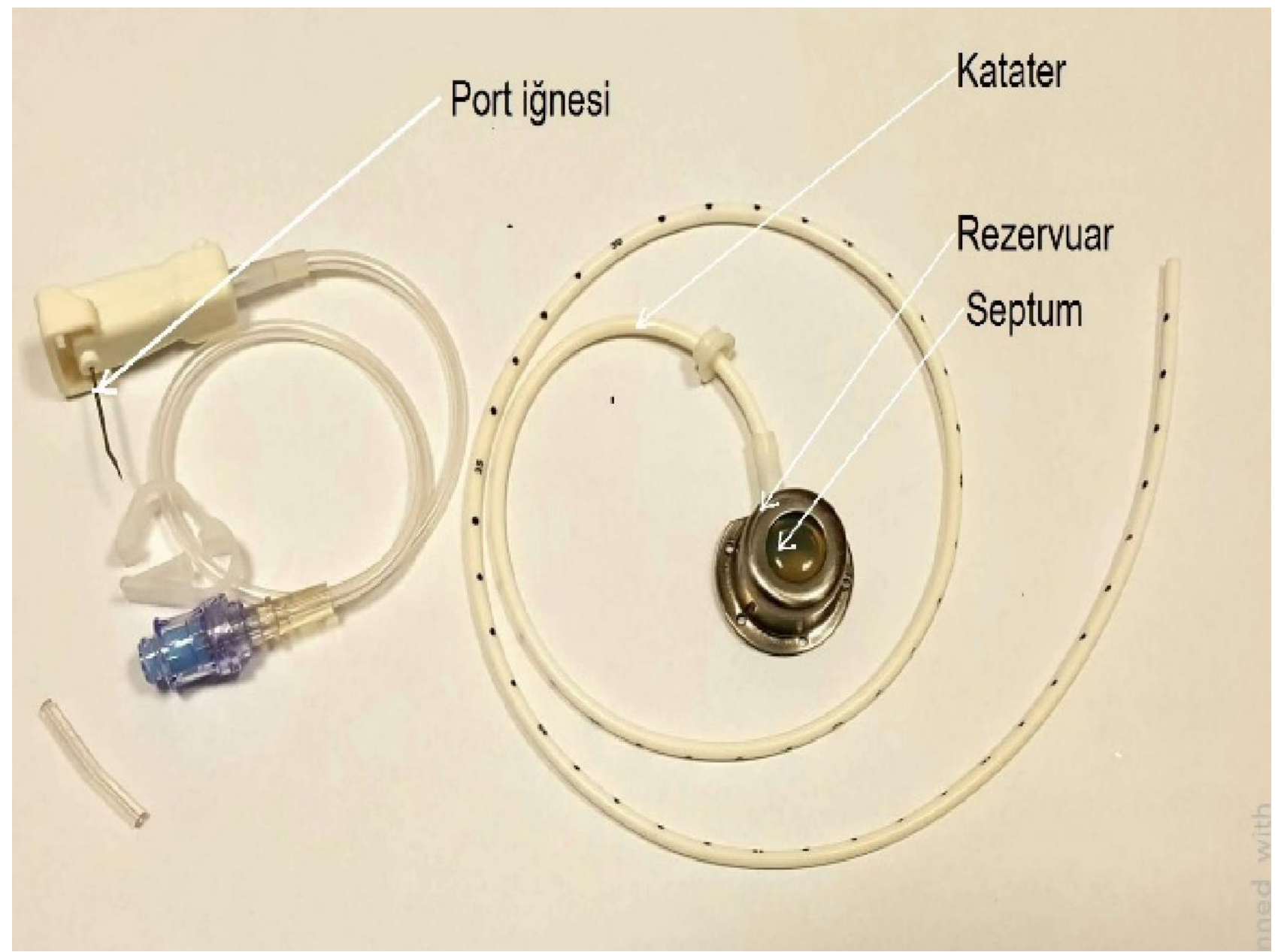

Şekil 6. Rezervuar, kateter ve huber port iğnesi

Dosya taramasından çalışma grubumuzdaki SKVPK'i taktığımız hastaların 218 'inin $(\% 94,4)$ aynı cerrahi ekip tarafindan takıldığ 1 tespit edildi. $\mathrm{Bu}$ hastalardan hiç birinde pnömo-hemotoraks veya müdahale gerektirecek ciddi hematom gibi bir komplikasyon tespit edilmemiştir. Serimizdeki kateterlerde 206'sinda (\%89,2) İJV'in tercih edilmesi ve körleme ponksiyonla yapılmasına rağmen ilk ven ponksiyonunda ince uçlu iğne (22G) kullanmamızın da işleme bağlı erken komplikasyonları azalttığını düşünmekteyiz. Ancak bu yöntem SCV için iğnenin kısa kalması sebebiyle uygulanamadi. SCV hastalarında uygun anatomik pozisyon verilerek yaklaşı 15 derecelik trendelenburg pozisyonunda yüzü ve çenesi karşı tarafa bakacak şekilde klavikulanın altından normal port iğnesi ile ponksiyon yapıldı. Port iğnesi klavikulaya horizontal ve karşı omuz başını gösterecek şekilde ilerletildi. $\mathrm{Bu}$ işlemler sırasında yardımc vücuda paralel bir şekilde aşağıya doğru çekti. Arter ponksiyonunda klavikulanın alt ve üstünden 15 dakikalık tampon uyguland1. $\mathrm{Bu}$ teknikle taktığımız SKVPK'inden hiç birinde hematom, pnömotoraks veya hemotoraks vakas1 gözlenmedi.

Port kateter ile ilgili bir diğer komplikasyon rezervuar üzerindeki cildin nekroza uğramasıdır. Bu daha çok cilt altı yăg 
dokusu ince ve zayıf hastalarda görülür. ${ }^{1}$ Çalışma grubumuzda port kateter taktığımız bir hastamızda 9 ay sonra rezervuarın cildi erode ederek septum kısmı dışarıdan görünecek şekilde cilt defekti oluşturduğu tespit edildi. Bu hastadan port cebinden kültür alındığı, debritman yapılarak antiseptik solüsyon ile temizlendiği ve rezervuarın cilt altına yerleştirilerek cildin kapatıldığı dosya taramasından anlaşıldı. Ancak bu hastamızda kültüründe üreme olmamasına rağmen zayıf cilt-alt1 yapısından dolayı süturlarının açılması nedeniyle kateteri çekilerek karşı taraftan yeniden port kateteri takıldı $\breve{g}_{1}$ tespit edildi.

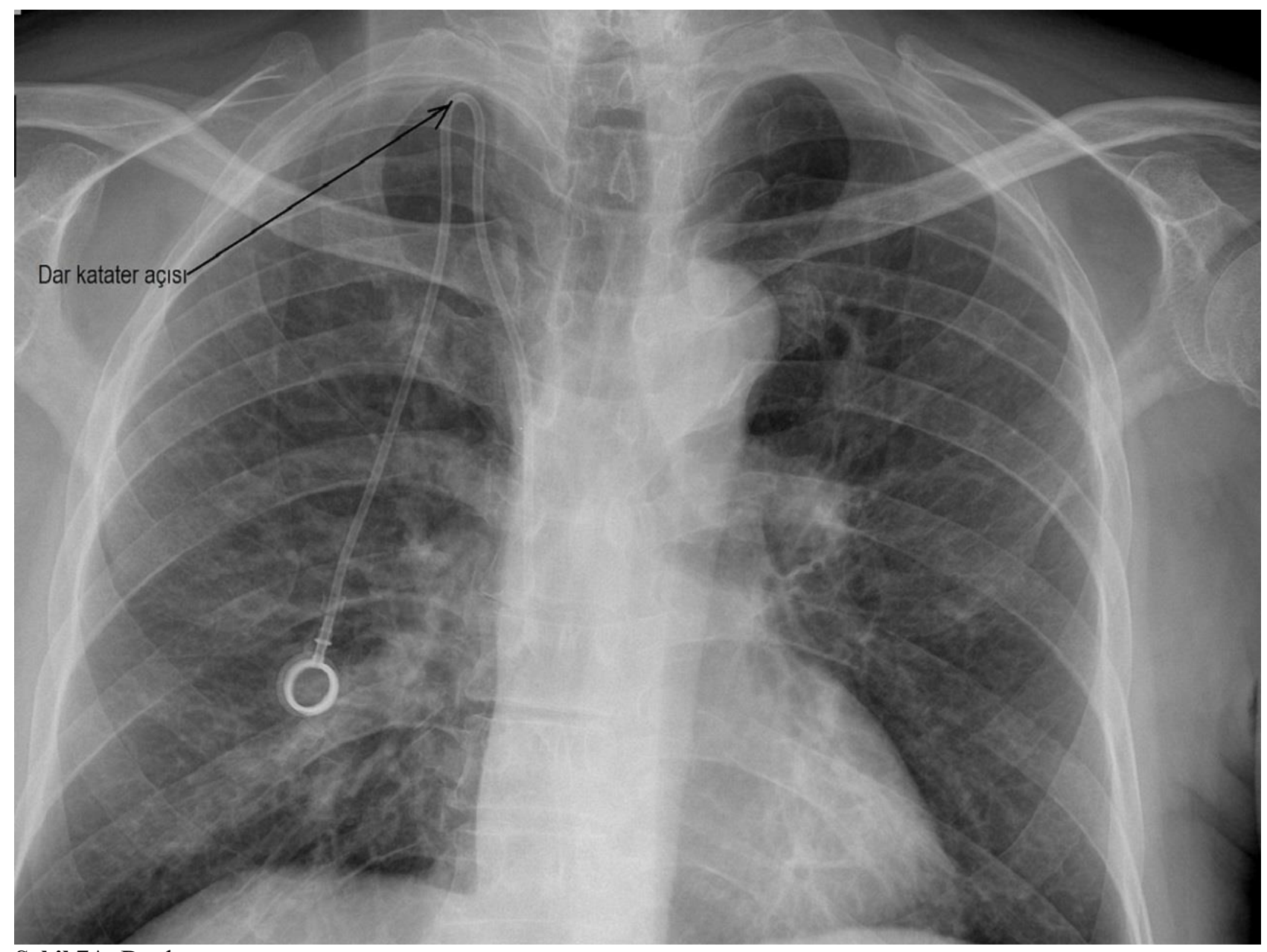

Şekil 7A. Dar kateter açısı.

Obez hastalarda geniş açılan cep ve rezervuarın iyi tespit edilmediği olgularda rezervuarın ters dönmesi olas1 malpozisyonlardandır. Ancak port cebi uygun genişlikte (dar) açılırsa sütür atmak gerekmeyebilir. ${ }^{16}$

Bizim port kateteri taktığımız obez bir hastamız 7 ay sonra son kemoterapi küründe, özellikle ponksiyon (kan alma ) sirasinda sorun yaşadığ 1 gerekçesiyle onkoloji kliniğince servisimize gönderildiği ve çekilen akciğer grafisinde rezervuarın ters döndüğü anlaşılması üzerine port rezervuar revizyonu uygulandi tespit edildi.
Kemoterapi alan kanser hastaları immün supresyon nedeniyle enfeksiyonlara açiktırlar. Her ne kadar port kateterler diğer santral venöz kateterlerden daha dirençli olsalar da literatür taramasında enfeksiyon sıklığ $1 \% 0,6$ 27 oranındadır. Bizim serimizde SCV yoluyla port takılan bir hastamızda $(\% 0,4)$ enfeksiyon bulguları gözlenmiş ve bu değer literatüre göre daha düşük olduğu görülmüştür. Kateter enfeksiyonunda çeşitli risk faktörleri suçlanır. Bunlardan biri de kateter uzunluğudur. ${ }^{17}$

Kliniğimizde kateter işlemlerinde rutin antibiyotik profilasisi yapilmamaktadır. İşlemler ameliyathane şartlarında ve asepsi antisepsi kurallarına uyularak yapıldığından hiçbir hastamızda enfeksiyon vakasına 
rastlanılmadi. Ancak subklavyan port taktığımız bir hastamızda 45 gün sonra rezervuar bölgesinde kızarıklık, ağrı ve hafif ateş şikayeti ile polikliniğimize başvurduğu, yapilan tetkiklerde enfeksiyon parametrelerinde yükseklik tespit edildiği ve başka bir odak olmaması üzerine hastanın port kateterinin çekildiği tespit edildi. $\mathrm{Bu}$ hastanın port kateterinden alınan kültürde üreme olmadığ1 ve karş1 taraftan yeni port kateterin takıldığ 1 dosya taramasından anlaşıld.

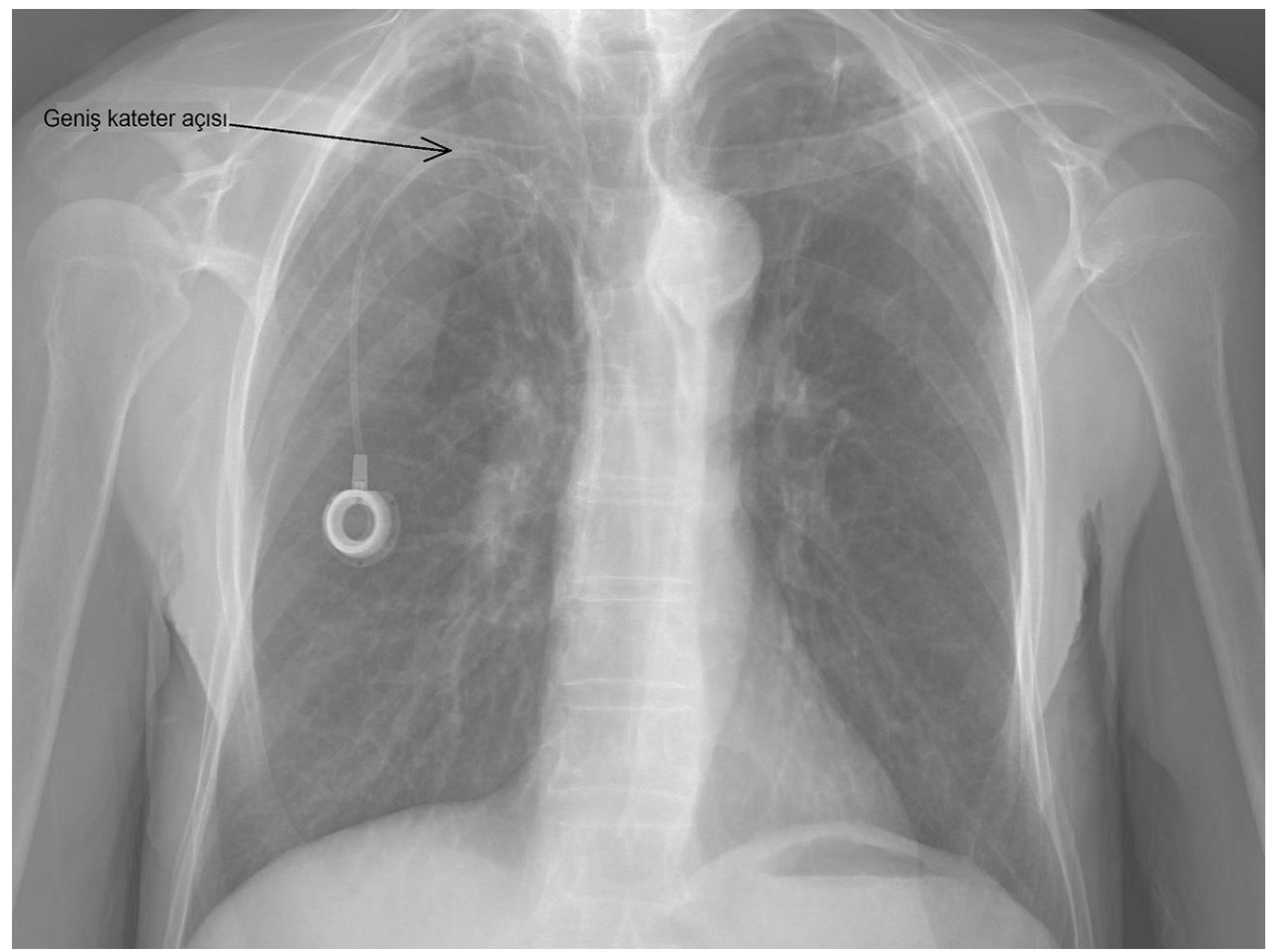

Şekil 7B. Geniș kateter açısı

Kateter boyunun ayarlanmasinda literatürde kullanılan ve antropometrik ölçümlere, matematiksel formüllere dayanan çok çeşitli yöntemler mevcuttur. Bunlar arasında en sık kullanılan yöntem Peres ve Czepizak formülleridir. ${ }^{18,19}$ Ancak tüm bu formüllerde değişik popülasyonlar için modifikasyonların yapılması gerekmektedir. Biz pratikte kullanım kolaylığı açısından bu formüllerin hiç birini kullanmadık; Öncelikle 3'üncü interkostal aralık (kateterin sıfır markırı burada olacak şekilde), klavuz telin cilde giriş bölgesi ve port rezervuarı arasındaki uzunluk işaretlendi (Şekil 5. [AC]). $\mathrm{Bu}$ ölçüm kaydedildi. Ven ponksiyonundan sonra guide EKG monitörizasyonunda aritmi görülünceye kadar ven lümenine ilerletildi. Daha sonda guide aritmi kayboluncaya kadar yaklaşık 3-4 cm geri çekilerek üzerindeki markırlarla yeni bir ölçüm alındı (Şekil 5. [AB]). $\mathrm{Bu}$ iki ölçümün toplamı takılan kateterin toplam uzunluğunu veriyordu. $\mathrm{Bu}$ teknik ile yerleştirilen port kateter uygulamalarımızda işlem sonrası çekilen akciğer grafilerin incelenmesinde port kateter ucunun sağ atriyum veya atriyokaval bileşkede yer aldığı ve hiç birinde herhangi bir malpozisyon görülmediği dosya taramasından anlaşıldı. Optimum katater boyu Czepizak formülüne göre sağ girişimlerde 16$17 \mathrm{~cm}$, sol girişimlerde 20,5-21,5 cm olarak hesaplanır. Gereğinden uzun tutulan kateterlerin kırılması, king yapmas1, tromboze olmas1, kardiyak aritmilere sebep olmas1 ve enfeksiyona zemin hazırlamas1 olas1 komplikasyonlardandır. ${ }^{17-19} \quad$ Bizim 
kullandığımız teknikle serimizde, sağ girişimlerde yaklaşık 17-18m, sol girişimlerde ise $20-21 \mathrm{~cm}$ ile literatür ile uyumlu idi (Tablo 1).

Kateter takılması kadar kullanımının da profesyonel ekiplerce yapılması önem taşımaktadır. Uygun yöntem ve uygun bakım protokolleriyle asepsi ve antisepsi kurallarına uyularak kullanılan port kateterler uzun aylar, hatta yıllar boyunca kullanılabilmektedir

\section{Sonuç}

Subkutan venöz port kateterleri kanser hastalarında uzun tedavi uygulamalarında oldukça kullanışlı cihazlardır. Uygun teknik ve tecrübeli ellerle takıldığında minimal komplikasyon ile kişinin uzun zaman alan tedavi süreçlerinde tedaviye hasta uyumunu artıracak ve yaşam kalitesini artıracaktır. Başarı ve minimal komplikasyon için bu işin deneyimli tek bir cerrahi ekip; ve mümkün ise tek bir kardiyovasküler ekip tarafindan yapılması gerekliliğini savunmaktayı. Böylelikle muhtemel mortal cerrahi komplikasyonlar, zamanında ve etkin birşekilde, zaman kaybetmeden müdahale edilebilinecektir.

\section{Araştırmanın Etik Boyutu}

İlgili üniversitenin Girişimsel Olmayan Klinik Araştırmalar Etik Kurulu'ndan gerekli izin alındiktan sonra (17.09.2019-2019/6-1) çalışma gerçekleştirilmiştir. Yazar çalışmaya dahil edilen gönüllüler üzerinde yapılan tıbbi araştırmada etik ilkeler hususunu içeren Helsinki Bildirgesi'ne ve geliştirilmiş en son şekline uyarak çalışmayı gerçekleştirmiştir.

\section{Bilgilendirilmiş Onam}

Dosya kullanılarak gerçekleştirilmiş bir retrospektif arşiv taramasıdır. Bu yüzden aydınlatılmış onam formları imzalattırılmamıştır.

\section{Yazar Katkıları}

Sunulan makale yazarın orijinal
çalışmasıdır.

\section{Çıkar Çatışması Beyanı}

Yazarın herhangi bir çıkara dayalı ilişkisi yoktur.

\section{Araştırma Desteği}

Çalışmayı maddi olarak destekleyen kişi/kuruluş yoktur.

\section{Kaynaklar}

1. Biffi R, De Braud F, Orsi F. et al. A randomized, prospective trial of central venous ports connected to standard open-ended or Groshong catheters in adult oncology patients. Cancer. 2001;92:1204-1212.

2. Stanislav GV, Fitzgibbons RJ Jr, Bailey RT Jr. et al. Reliability of implantable central venous access devices in patients with cancer. Arch Surg. 1987;122:1280-1283

3. Di Carlo I, Cordio S, La Greca G. et al. Totally implantable venous access devices implanted surgically: a retrospective study on early and late complications. Arch Surg.. 2001;136:1050-1053.

4. Sticca RP, Dewing BD, Harris JD. Outcomes of surgical and radiologic placed implantable central venous access ports. Am J Surg. 2009;198:829-833.

5. Özdemir NY, Abalı H, Oksüzoğlu B, Budakoğlu B,Akmangit I, Zengin N. It appears to be safe to start chemotherapy on the day of implantation through subcutaneous venous port catheters in inpatient setting. Support Care Cancer. 2009;17:399-403.

6. McGee DC, Gould MK. Preventing complications of central venous catheterization. $N$ Engl J Med. 2003;348:1123-1133.

7. Güleç G, Büyükkınacı A. Kanser ve Psikiyatrik Bozukluklar. Psikiyatride Güncel Yaklaşımlar-Current Approaches in Psychiatry. 2011;3(2):343-367

8. Singh KR, Agarwal G, Nanda G et al (2014) Morbidity of chemotherapy administration and satisfaction in breast cancer patients: a comparative study of totally implantable venous access device (TIVAD) versus peripheral venous access usage. World J Surg. 38 (5) :1084-1092.

9. Gyves J, Ensminger W, Neiderhuber J, et al. Totally implanted system for intravenous chemotherapy in patients with cancer. Am J Med. 1982;73:841-845.

10. Iannacci L, Piomelli S. Supportive care for children with cancer. Guidelines of the Children's Cancer Study Group. Use of venous access lines. Am J Pediatr Hematol Oncol.. 1984;6:277-281.

11. Güleser GN ve Taşçı S. Onkolojide Sık Kullanılan Santral Venöz Kateterleri ve Bakımı. F.Ü.Sağ.Bil.Tıp Derg. 2009;23 (1):47-51

12. Samancı T, Mandel NM, Bozkurt AK, Kutlu F, Uras C. 115 Kanser hastasında port komplikasyonlarının değerlendirilmesi. Cerrahpaşa Tıp Dergisi. 2004;35;71-77.

13. Green E, Macartney G, et al. Managing central venous access devices in cancerpatients: A clinical practice guideline. CONJ/RCSIO-2008. doi:10.5737/1181912x18219.

14. Cowl CT, Weinstock JV, Al-jurf A, Ephgrave K, Murray JA, Dillon K. Complications and cost associated with parenteral nutrition delivered to hospitalized patients through either subclavian or peripherally-inserted central catheters. Clin Nutr. 2000;19:237-243.

15. Wigmore TJ, Smythe JF, Hacking MB, Raobaikady R, MacCallum NS. Effect of the implementation of NICE guidelines for ultrasound guidance on the complication rates associated with central venous catheter placement in patients presenting for routine surgery in a tertiary referral centre. British Journal of Anaesthesia.. 2007;99:662-665.

16. Kesici S, Carus H, Turgut N, Ünlü N, Altan A, Kesici U. Başarılı Venöz Port Kateterizasyonu Sonrası Kateterin Spontan Yer Değişmesi. Okmeydanı Tıp Dergisi. 2011;27(1):49-53,

17. Yıldızeli B, Laçin T, Batirel HF, Yüksel M. Complications and management of long-termcentral venous accesscatheters and ports. J Vasc Access. 2004;5: 174-178.

18. Peres PW. Positioning central venous catheters a prospective survey. Anaesth Intensive Care, 1990;18(4):536-9.

19. Czepizak CA, O'Callaghan JM, et al. Evaluation of formulas for optimal positioning of central venous catheters. Chest. $1995 ; 107 ; 1662-1664$ 